\title{
Calcinosis cutis universalis - a rare manifestation of systemic lupus erthyematosus
}

\author{
F E Suleman, MB ChB, FC Rad (Diag), M Med Rad (Diag) \\ Department of Radiology, University of Pretoria
}

M M T M Ally, MB ChB, FCP

Department of Internal Medicine, University of Pretoria

Corresponding author: F Suleman (fesuleman@gmail.com)

\begin{abstract}
Calcinosis cutis (or skin and subcutaneous calcification) is a feature of a variety of rheumatic conditions (most commonly dermatomyositis and scleroderma), but is rarely reported in systemic lupus erythematosus (SLE ). When calcinosis cutis does occur in patients with SLE, it tends to be localised (circumscripta) rather than generalised (universalis). We report a case of a 21-year-old woman who presented to us with a 6-year history of SLE and the rare occurrence of calcinosis cutis universalis.
\end{abstract}

\section{Introduction}

Calcinosis cutis is a well-known phenomenon in a variety of rheumatic conditions, particularly dermatomyositis, scleroderma and CREST (calcinosis, Raynaud's phenomenon, oesophageal dysfunction, sclerodactyly and telangiectasia) but is rarely described in systemic lupus erythematosus (SLE) ${ }^{1,2}$ A review of the literature reveals that, up to 2010, only 37 cases were reported in the English-language literature. ${ }^{1}$

Calcinosis cutis associated with SLE is dystrophic in nature and nearly always localised (calcinosis cutis circumscripta) but may infrequently occur as a generalised form referred to as calcinosis cutis universalis. ${ }^{1}$ It is described predominantly in females and may manifest anytime from 6 months to 18 years after the diagnosis of SLE. ${ }^{3}$

We describe the case of a 21-year-old woman presenting with calcinosis cutis universalis, 6 years after being diagnosed with SLE.

\section{Case report}

A 21-year-old woman was referred to our rheumatology clinic for management of known active SLE. She had been diagnosed at her local hospital 6 years previously but had not received any specialist care. She was again admitted to her local hospital 6 months prior to the current referral with a diagnosis of pneumonia, but claimed to have had no improvement with therapy and she continued to cough and lose weight. Her current complaints were polyarthritis involving the small joints of her hands,elbows and knees with associated morning stiffness.

On examination, she appeared chronically affected. She had a malar rash and widespread hyperpigmented skin lesions with palpable hard deposits in the soft tissue. She was pale, had muscle weakness, was tender around most joints and demonstrated evidence of healed vasculitic lesions on both hands and feet. Ulcers were noted on her thighs. The rest of the physical examination was within normal limits.

Blood results came back positive for antinuclear antibodies and doublestranded DNA antibodies. This, in combination with clinical findings, fulfilled the American Rheumatism Association criteria for a diagnosis of SLE. Raised inflammatory markers were in keeping with active disease. Her serum calcium and phosphate levels were within normal limits. Her renal function was normal but urine dipstix demonstrated proteinuria, and a renal biopsy confirmed class 3 lupus nephritis.

Her chest radiograph showed a right pleural effusion with cardiomegaly (Fig. 1), and radiographs of the hips and hands demonstrated widespread calcifications in the soft tissue and no evidence of arthropathy (Figs 2a and b). A computer tomography (CT) scan confirmed the findings noted on the chest radiograph and further demonstrated calcifications around the shoulder and in the breast and back (Fig. 3). The soft tissue calcifications noted on the other radiographs were confirmed to be in the subcutaneous tissue and found to be more widespread in the lower limbs than noted on the plain film radiographs (Fig. 4).

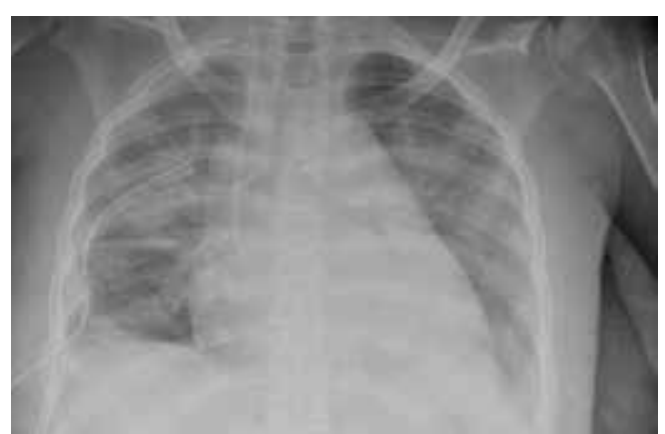

Fig. 1. Chest radiograph demonstrates cardiomegaly with a right pleural effusion.

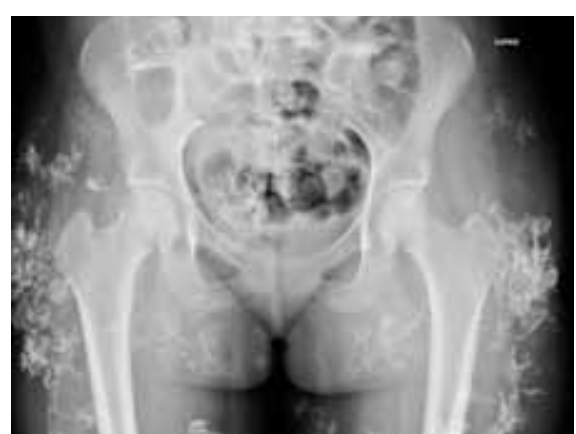

Fig. 2a. Frontal radiograph of the pelvis demonstrating extensive soft-tissue calcification.

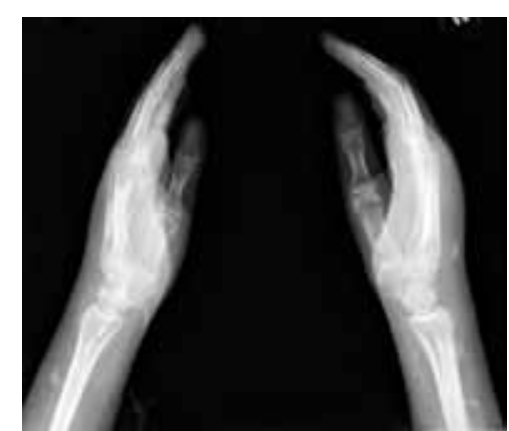

Fig. 2b. Lateral radiograph of the hands including the wrists demonstrates softtissue calcifications of the forearm. 


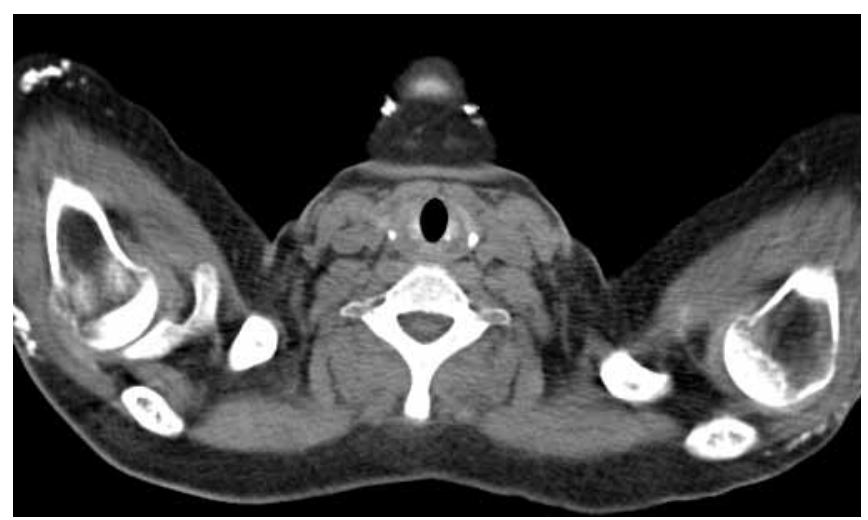

Fig. 3. Axial CT scan at the level of the shoulders demonstrates soft-tissue calcifications in the subcutaneous tissue around the shoulders.

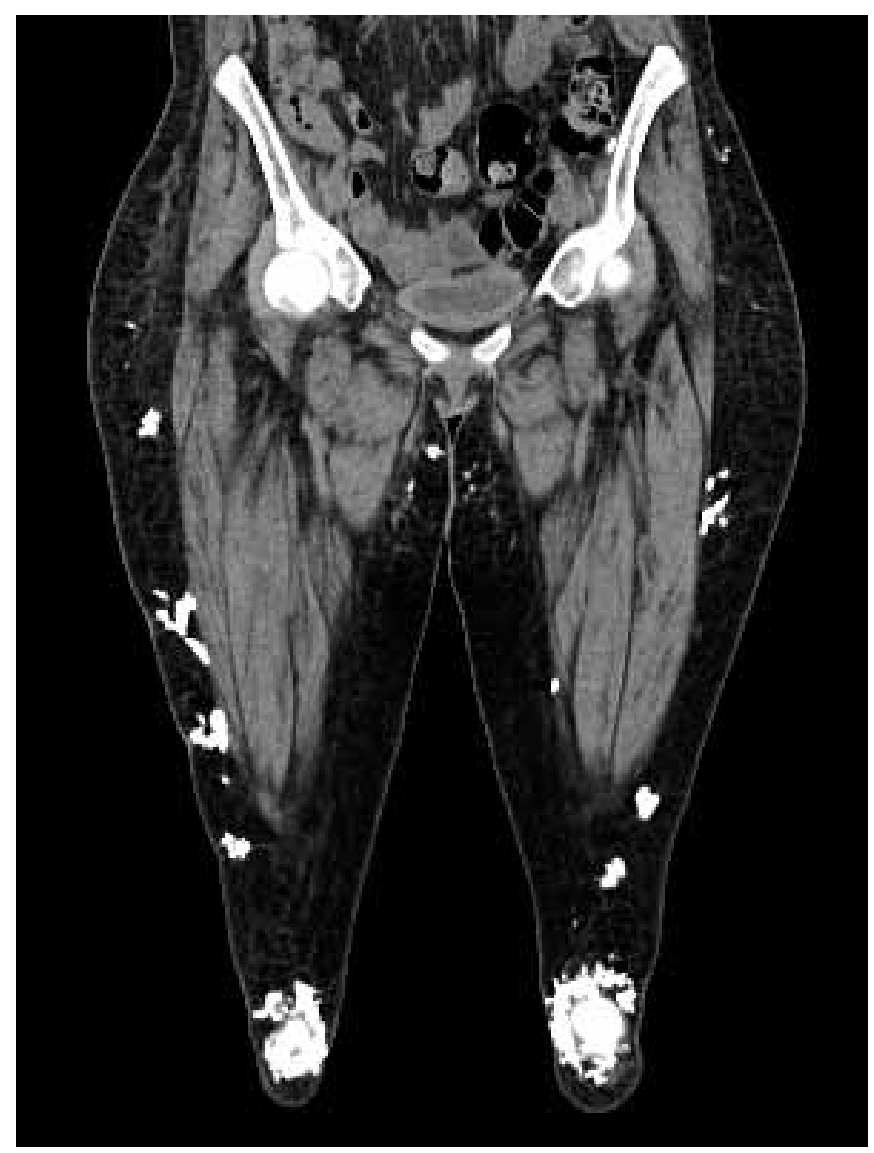

Fig. 4. Coronal CT scan of the proximal lower limbs demonstrate extensive calcifications in the subcutaneous tissue around both knees as well as both thighs.

The dermatologists confirmed that the skin lesions were in keeping with SLE. A diagnosis of calcifying panniculitis owing to SLE was considered, but a skin biopsy showed no significant inflammatory infiltrate; a final diagnosis of calcinosis cutis universalis associated with SLE was made.

\section{Discussion}

Soft-tissue calcifications may be classified into metastatic (abnormal serum calcium-phosphorus levels), tumoral (elevated phosphorus but normal calcium levels), dystrophic including calcinosis (normal serum calcium-phosphorus levels but damaged tissue), idiopathic (no abnormalities detected) and calciphylaxis (chronic renal failure with abnormal calcium-phosphorus levels). ${ }^{4}$ Calcifications occurring in the skin and subcutaneous tissue of patients with SLE are dystrophic/ calcinotic in nature. ${ }^{1,2,5}$ The mechanism of this complication is poorly understood, and it is not known why some patients with SLE develop this condition and others do not. ${ }^{3-5}$

Calcinosis cutis may involve a localised region, in which case it is referred to as calcinosis cutis circumscripta and, in its more generalised form, as calcinosis cutis universalis. Only 37 cases have been described in the English-language literature in patients with SLE, and nearly always circumscripta in distribution. ${ }^{1}$ The condition typically occurs in females with a predilection for the extremities, buttocks and periarticular extensor surfaces. ${ }^{2,4}$ Our patient had involvement of her extremities, buttocks, trunk and breast, with peri-articular deposits around the knees and shoulders. Commonly, the skin and subcutaneous fat are involved but the deeper soft tissues may also be affected. ${ }^{2}$ The calcified material may form palpable nodules, induce muscle atrophy and predispose to the formation of contractures. ${ }^{4}$ Local inflammation may occur, leading to ulceration and extrusion of calcified material., Our patient had ulcerative, discharging lesions on her thighs.

Soft tissue calcifications may be easily demonstrated on plain radiographs, but $\mathrm{CT}$ scan is more effective in demonstrating the location and extent of calcifications. In our patient, a CT scan confirmed the subcutaneous distribution of calcifications and demonstrated far more extensive involvement than initially suspected clinically and on plain films.

Calcinosis cutis has been described as severe, damaging, ${ }^{6}$ disfiguring and painful. ${ }^{5}$ It rarely resolves spontaneously, and the various pharmocological treatment options have had poor success rates. ${ }^{4}$ Surgery may be an option for symptomatic relief or very large lesions, ${ }^{3,4}$ but further research is necessary to develop effective treatment.

\section{Conclusion}

Calcinosis cutis universalis is a rare complication of SLE that can be demonstrated on plain radiographs and more easily on CT. Clinically, it may be confused with a diagnosis of lupus panniculitis, and a biopsy is essential to confirm the diagnosis. It may be a source of pain and significant disability; no effective therapy is available at present.

\footnotetext{
1. Kim MS, Choi KC, Kim HS, Song IG, Shin BS. Calcinosis cutis in systemic lupus erythematosis: A case report and review of the published work. J Dermatol 2010;37:815-818.

2. Tristano AG, Villarroel JL, Rodriguez MA, Millan A. Calcinosis cutis universalis in a patient with systemic lupus erythematosus. Clin Rheumatol 2005;25:70-74.

3. Minami A, Suda K, Kaneda K, Kumakiri M. Extensive subcutaneous calcifications of the forearm in systemic lupus erythematosus. J Hand Surg (Br) 1994;5:638-641.

4. Boulman N, Slobodin G, Rozenbaum M, Rosner I. Calcinosis in rheumatic diseases. Semin Arthritis Rheum 2005;34:805-812.

5. Mandelbrot DA, Santos PW, Burt RK, et al. Resolution of SLE-related soft-tissue calcification following haemopoetic stem cell transplantation. Nephrol Dial Transplant 2008;23:2679-2684.

6. Wollina U, Hein G. Lupus erythematosus: uncommon presentations. Clin Dermatol 2005;23:470-479.
} 